\title{
ANÁLISE DOS INDICADORES DO PROCESSO DE DOAÇÃO DE ÓRGÃOS E TRANSPLANTES NO ESTADO DO PARÁ
}

\author{
Analysis of organ transplantation markers and the donation process in the state of Pará
}

Karolina de Sousa Neves ${ }^{1,}$ Clayton Gonçalves Almeida², Heloisa Paglione ${ }^{3}$

\section{RESUMO}

Introdução: Mesmo com os grandes avanços, a escassez de órgãos ainda é um grande problema de saúde pública no Brasil. O processo de doação é definido de maneira geral como o conjunto de ações e procedimentos que, agindo juntos e de forma eficaz, conseguem transformar um potencial doador em doador efetivo. Surgiu então a necessidade de buscar as reais causas que levam ao grande número de perdas de doações de órgãos que, na maioria dos casos, só podem ser mensuradas através de indicadores. Objetivo: Analisar e descrever os indicadores utilizados pela Organização de Procura de Órgãos (OPO), no estado do Pará. Material e Métodos: Trata-se de uma pesquisa de abordagem quantitativa e descritiva de corte transversal, onde foi analisada a base de dados da OPO, do Hospital Regional do Baixo Amazonas "Dr. Waldemar Penna", e seus indicadores de número de potenciais doadores notificados à Central de Transplantes do estado do Pará, contraindicação médica, processos não concluídos, recusa familiar e doador efetivo. Foi utilizado o software Excel para realização da tabulação das informações obtidas, ao final da pesquisa, e depois transformados em gráficos disponíveis no Word. Resultados: A análise mostrou aumento no número de notificações de potencial doador, porém, houve redução no número de morte encefálica confirmada, devido ao aumento no índice de processos não concluídos. Conclusão: Entre as ações de melhoria do processo, estão a implantação de uma comissão intra-hospitalar no Hospital Municipal de Santarém e atividades relacionadas à educação continua sobre identificação e manutenção de potenciais doadores.

Descritores: Indicadores; Morte Encefálica; Doação de Órgãos; Transplantes.

\footnotetext{
Instituições:

${ }^{1}$ Departamento de Procura de Órgãos do Hospital Regional do Baixo Amazonas, Santarém/PA

2 Departamento de Ensino da Universidade de Sorocaba, São Paulo/ SP

${ }^{3}$ Departamento de Pacientes Graves do Hospital Israelita Albert Einstein, São Paulo/SP

\section{Correspondência:}

Karolina de Sousa Neves

Travessa Silvino Pinto, $n^{\circ} 840$, Centro - Santarém/PA

Tel: (93) 991458359

karolinaneves@gmail.com
}

Recebido em: 20/08/2015
Aceito em: 16/09/2015

\section{INTRODUÇÃO}

O transplante de órgãos é um processo que se inicia com a autorização da doação de um órgão. Esse processo é definido como um conjunto de ações e procedimentos que transformam um potencial doador em um doador efetivo. $^{1}$

Esse processo requer tempo para que ocorra corretamente, respeitando-se todas as suas etapas, podendo levar horas ou dias, o que pode causar estresse e ser traumático à família do doador e, com isso, comprometer desfavoravelmente o número de doações. ${ }^{2}$

Existem etapas a serem seguidas durante o processo: identificação do paciente com critérios clínicos para morte encefálica (ME); diagnóstico de $\mathrm{ME}$, que 
envolve as avaliações clínicas e exame complementar; manutenção do potencial doador e entrevista familiar. ${ }^{3}$ Qualquer falha nessas etapas limita a doação de órgãos e impede que o processo seja concluído. ${ }^{4}$

A lei que regulamenta os transplantes em todo o território nacional é a Lei $n^{\circ} 9434 / 1997$ e o Decreto $n^{\circ} 2268$, que dispõe sobre a remoção de órgãos, tecidos e partes do corpo humano para fins de transplante. ${ }^{5}$ Porém, um número cada vez menor de potenciais doadores tem sido notificado e sabe-se que a notificação à Central de Notificação, Captação e Doação de Órgãos (CNCDO) de potencial doador é compulsória, prevista em lei. ${ }^{4}$

As equipes multiprofissionais que atuam no processo de doação de órgãos relatam que a falta de conhecimento técnico e de comprometimento/profissionalismo têm um impacto negativo no processo, influenciando, tanto a decisão familiar sobre a autorização da doação, quanto a tomada de decisão da equipe de profissionais de saúde, ocasionando a demora na identificação de potenciais doadores e a não realização ou a realização tardia do protocolo de ME. ${ }^{6-9}$

Mesmo com os grandes avanços, a escassez de órgãos ainda é um grande problema e por essa razão surgiu a necessidade de buscar as reais causas que levam ao grande número de perda de doações de órgãos, em países desenvolvidos e subdesenvolvidos. ${ }^{10,11}$

No Brasil, apesar de haver leis bem claras e eficientes a respeito do processo de doação de órgãos e transplantes, não há instrumentos que possam mensurar a real potencialidade de ME nos hospitais. ${ }^{11-13}$

Com o propósito de medir aspectos relacionados à estrutura, processos e resultados, os indicadores fornecem informações que direcionam iniciativas de melhoria de qualidade, chamando a atenção para assuntos mais específicos dentro de uma instituição de saúde. ${ }^{14}$

Os resultados contemplam as taxas de notificação, doação e não doação, gerais e classificadas, segundo: não autorização familiar, ME não confirmada, contra indicação médica, parada cardiorrespiratória e infraestrutura inadequada. ${ }^{14}$

\section{MÉTODO}

Trata-se de um estudo quantitativo, descritivo, de corte transversal e retrospectivo. A pesquisa foi realizada na Organização de Procura de órgãos (OPO), situada no Hospital Regional do Baixo Amazonas "Dr. Waldemar Penna", localizado na cidade de Santarém, estado do Pará.

Foram utilizados os indicadores alimentados pela OPO, através de uma base de dados de preenchimento da equipe, onde foram utilizadas as informações contidas nos prontuários dos potenciais doadores.

Os dados foram inseridos em uma planilha do software Microsoft Excel e, em seguida, transformadas em gráficos disponíveis no software Microsoft Word; após isso, foi realizada uma análise estatística descritiva, onde foram observados os indicadores de números de notificações dos potenciais doadores, mortes encefálicas confirmadas, entrevista familiar, recusa familiar, contra indicações, processos não concluídos e doadores efetivos.

\section{RESULTADOS}

Foram analisadas 65 notificações de potenciais doadores da OPO à CNCDO, entre o ano de 2012 e o $1^{\circ}$ semestre de 2015, que compõem os indicadores da OPO, entre eles: notificações de potencial doador, ME confirmada, entrevista familiar, recusa familiar, doações efetivas, processos não concluídos (interrupções entre $1^{\circ}$ e $2^{\circ}$ exame; $2^{\circ}$ exame e exame complementar; exame complementar e entrevista familiar) e contra indicações absolutas.

Na Figura 1, é possível verificar que o número de notificações foi aumentando no decorrer dos anos, apesar de pequena queda em 2013, com apenas 10 notificações, ressaltando que, em 2012, ainda funcionava como Comissão Intra-hospitalar de Doação de Órgãos e Tecidos para Transplantes (CIHDOTT), com abrangência apenas no Hospital Regional do Baixo Amazonas, onde não há atendimento de urgência e emergência. Mesmo com o aumento de notificações, chegando no $1^{\circ}$ semestre de 2015 a 19 notificações, as ME confirmadas diminuíram, devido ao número de processos não concluídos e interrupções do protocolo de $\mathrm{ME}$, sendo que no atual ano, 11 notificações não tiveram seu protocolo encerrado devido a parada cardiorrespiratória (Tabela 1).

O número de ME confirmadas em 2012 e em 2014 foi de 12 protocolos confirmados com todos os exames realizados $\left(1^{\circ}\right.$ e $2^{\circ}$ exames clínicos e exame complementar), sendo que em 2012 não houve paciente com contra indicação médica e em 2014 houve três casos com contra indicação médica, inviabilizando a entrevista familiar e, consequentemente, a doação de órgãos, conforme a Figura 2 e Tabela 1.

$O$ indicador representado na Figura 3 permite identificar que o número de doações efetivas diminuiu consideravelmente em 2014, chegando a não ter nenhuma em 2015. De oito casos de ME confirmada, três tiveram contra indicação médica, em cinco, as famílias foram entrevistadas, e esses cinco tiveram recusa de doação de órgãos. 
Figura 1 - Processo de Doação da OPO no período de 2012 ao $1^{\circ}$ semestre de 2015.

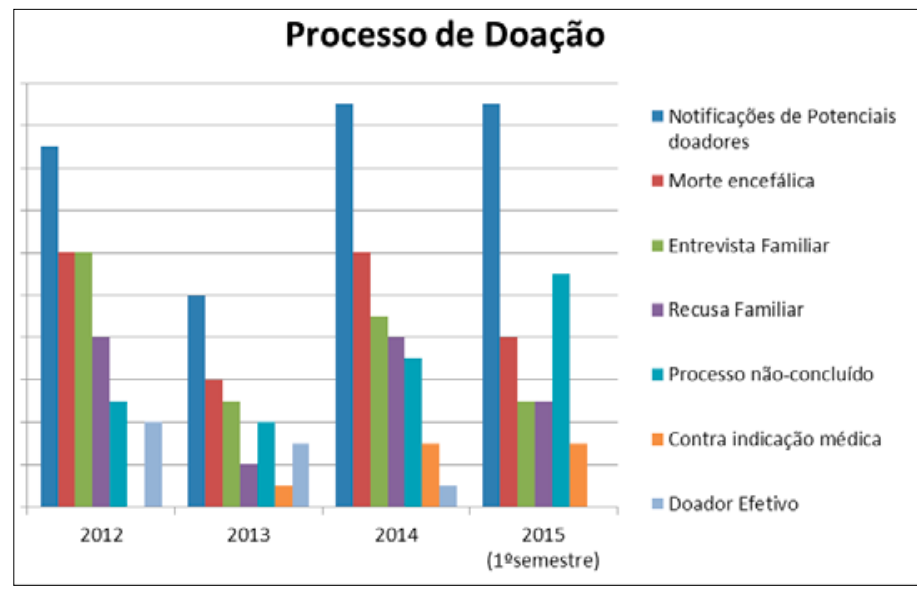

Tabela 1 - Histórico dos indicadores na OPO do estado do Pará.

\begin{tabular}{lccccc}
\hline \multicolumn{1}{c}{ Indicadores } & $\mathbf{2 0 1 2}$ & $\mathbf{2 0 1 3}$ & $\mathbf{2 0 1 4}$ & $\begin{array}{c}\mathbf{2 0 1 5} \\
\left(\mathbf{1}^{\mathbf{0}} \text { semestre }\right)\end{array}$ & Total \\
\hline $\begin{array}{l}\text { Notificações } \\
\text { de Potenciais } \\
\text { doadores }\end{array}$ & 17 & 10 & 19 & 19 & 65 \\
$\begin{array}{l}\text { Morte Encefálica } \\
\text { Entrevista familiar }\end{array}$ & 12 & 6 & 12 & 8 & 38 \\
\hline $\begin{array}{l}\text { Recusa familiar } \\
\text { Processo não }\end{array}$ & 8 & 2 & 8 & 5 & 23 \\
concluído & 5 & 4 & 7 & 11 & 27 \\
\hline $\begin{array}{l}\text { Contraindicação } \\
\text { médica }\end{array}$ & 0 & 1 & 3 & 3 & 7 \\
\hline \begin{tabular}{l} 
Doador efetivo \\
\hline
\end{tabular} & 4 & 3 & 1 & 0 & 8 \\
\hline
\end{tabular}

Figura 2 - Indicador de ME, processo não concluído e notificações no período de 2012 ao $1^{\circ}$ semestre de 2015

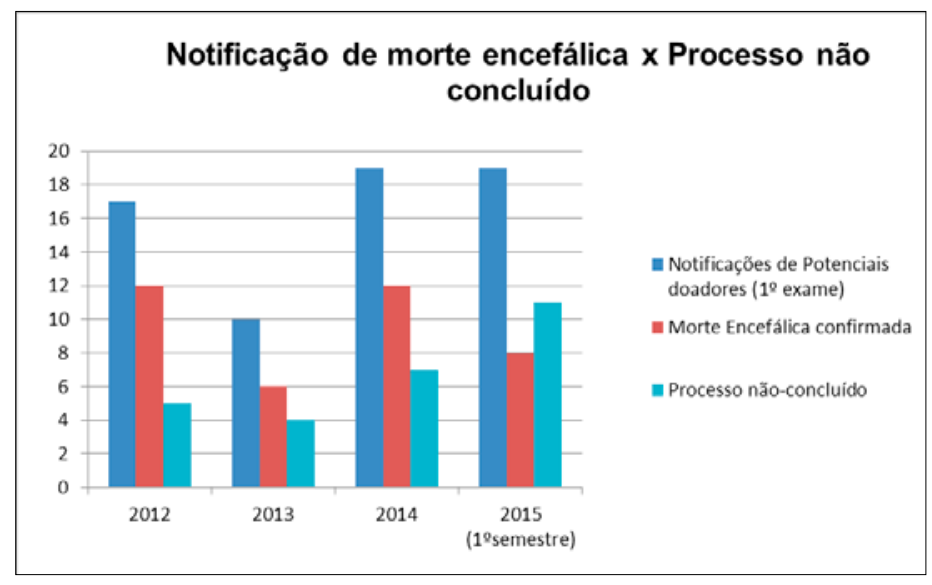

Figura 3 - Indicador de entrevista familiar e doações efetivas no período de 2012 ao $1^{\circ}$ semestre de 2015

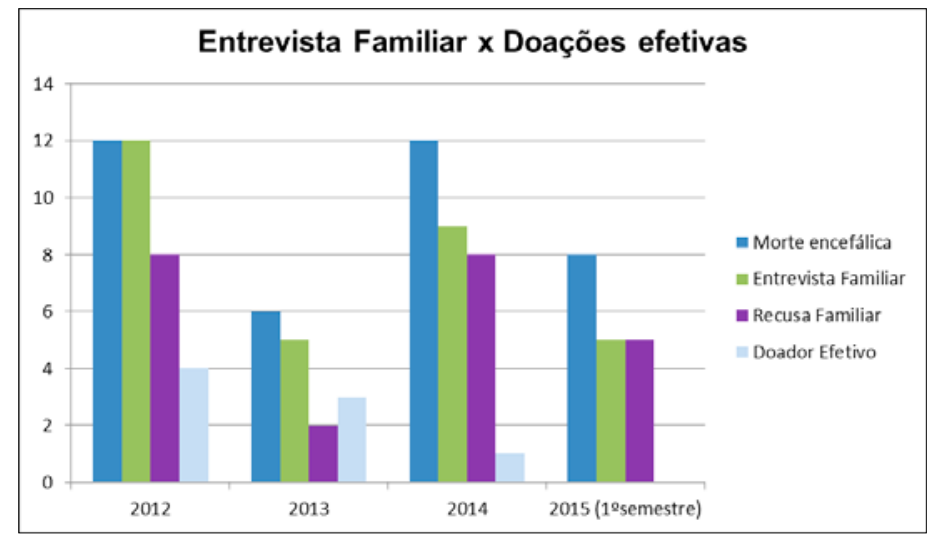

\section{DISCUSSÃO}

O Estado do Pará possui uma população de 7.581.051 habitantes, com 230 hospitais e, atualmente, há quatro OPO's em processo de implantação (etapa 2), sendo duas na capital do estado, Belém, e duas no interior, uma em Redenção e outra em Santarém, à qual o estudo se refere. ${ }^{15}$

É importante esclarecer que, nos anos de 2012 a 2014, existia apenas a CIHDOTT, e que a esta apenas realizava busca ativa de possíveis doadores dentro do Hospital Regional do Baixo Amazonas, onde era sediada. Após 2014, teve início o processo de implantação da OPO, que teria como abrangência apenas dois hospitais, sendo um com perfil oncológico e de alta complexidade, com serviços de neurocirurgia e unidades intensivas e o outro, o Hospital Municipal de Santarém- Pronto Socorro, que recebe a demanda de vários municípios da região.

Identificar esse déficit entre notificação de potenciais doadores e pacientes com ME permite reconhecer que o número de processos não concluídos é grande, todos devido a óbito dos pacientes por PCR, o que implica em outro quesito: a manutenção desses pacientes, que nos casos levantados de 2014 e primeiro semestre de 2015, apresentou aumento de sete casos para 11 processos não concluídos, eram de pacientes internados no Hospital Municipal de Santarém.

As dificuldades evidenciadas através dos indicadores do processo de doação de órgãos sugerem que os profissionais de saúde desconhecem os protocolos relacionados ao processo de doação de órgãos, a inexistência e/ou baixa efetividade das comissões intra-hospitalares/organizações de procura de órgãos, levando à grande perda de potenciais doadores e órgãos. ${ }^{14}$ 
Com base nesse levantamento, a OPO pode elaborar estratégias, como a criação de uma CIHDOTT no Hospital Municipal de Santarém e também a realização de treinamentos voltados para a identificação do possível doador e a manutenção do potencial doador com a equipe de reanimação e unidade de terapia intensiva.

É importante que haja interação entre os profissionais que prestam assistência ao potencial doador (paciente com diagnóstico de $\mathrm{ME}$, do qual tenham sido descartadas contraindicações clínicas que representem riscos aos receptores dos órgãos1), visando a qualidade na assistência do potencial doador e da família, o que pode contribuir para que, ao término, o processo seja favorável à doação de órgãos. ${ }^{2}$

Os fatores limitantes que contribuem para a não conclusão do processo e confirmação da ME são: falta de identificação precoce do potencial doador, falha na manutenção com o potencial doador, inadequada entrevista familiar e falta de educação continuada dos profissionais de saúde, ${ }^{3,16,17}$ resultando em problemas que interferem na taxa de doadores efetivos no Brasil, onde a defasagem entre os potenciais doadores e os doadores efetivos, que considerada baixa, esteja relacionada à contraindicação médica, manutenção do potencial doador (relacionada à demora na identificação do potencial doador), recusa familiar e problemas logísticos. ${ }^{15,18}$

Diante do alto índice de processos não concluídos relacionados à PCR e baixa efetividade de notificações, surge a necessidade de que os gestores de saúde, assim como os profissionais que atuam dentro do processo, busquem estratégias e ferramentas que sirvam para monitorar e gerenciar o sistema de doação de órgãos, avaliando continuamente todas as fases do processo, identificando as deficiências e criando estratégias para melhorá-las. ${ }^{8,19}$

\section{CONCLUSÃO}

O estudo permitiu analisar e descrever os indicadores utilizados por uma OPO do estado do Pará com base no processo de doação de órgãos e, com isso, propor ações de melhorias desses resultados.

Os problemas identificados no processo de doação de órgãos permitem conhecer a realidade do estado, diante da escassez e baixa efetivação de potenciais doadores, em comparação com o número de notificações. ${ }^{6}$

O acompanhamento e a utilização constante de indicadores relacionados ao processo de doação ajudarão a realizar um diagnóstico situacional das instituições hospitalares que são acompanhadas pela OPO, permitindo conhecer os fatores que interferem nesse baixo índice.

A implantação de uma CIHDOTT no Hospital Municipal de Santarém-Pronto Socorro também auxilia nas melhorias propostas, organizando o processo dentro do hospital e prestando auxilio à OPO quanto à melhor e mais rápida identificação dos potenciais doadores, prestando abordagem adequada aos familiares e articulação com a OPO e CNCDO, objetivando a doação efetiva dos órgãos. ${ }^{20}$

Concluiu-se também que são necessárias medidas de educação contínua entre os profissionais que atuam direta ou indiretamente no processo, a fim de contribuir para a diminuição do tempo na identificação do potencial doador e também na melhoria da manutenção deste.

\section{RESUMO}

Introduction: Even with great advancement, the organ shortage is still a major public health issue. In general, the donation process is defined as the set of actions and procedures that together can effectively change a potential donor into an effective donor. Therefore, it emerged the need to search for the real causes that lead to the great amount of losses of organ donation, and in most cases, this can only be measured by markers. Purpose: To analyze and describe markers used by the Organ Procurement Organization in the State of Pará. Material and methods: This is a cross sectional quantitative survey and descriptive approaching performed by analyzing database from the Organ Demand Organization, Hospital Regional do Baixo Amazonas "Dr. Waldemar Penna" and its markers as to the amount of potential donors notified to the Transplant Center in the State of Pará, medical contraindication, uncompleted processes, refusal from family and effective donor. The Excel software was used to tab the information attained and the final tabulation of the research, and transforming it into graphs in Word software. Results: The analysis showed an increase of notifications of potential donors; however, there was a reduction in the amount of confirmed brain death due to the increase in the index of uncompleted processes. Conclusion: Among the actions to improve the process it is deployed an intra-hospital Committee at Hospital Municipal de Santarém and continuing educational activities on identification and maintenance of the potential donor.

Descritores: Indicators, Brain Death, Organ Donation, Transplants. 


\section{REFERÊNCIAS}

1- São Paulo (Estado). Secretária de Estado da Saúde de São Paulo (SP). Coordenação do Sistema Estadual de Transplante. Doação de órgãos e tecidos. São Paulo (SP): SES, 2008.

2- Santos MJ, Massarollo MCKB. Processo de doação de órgãos: percepção de familiares de doadores cadáveres. Rev Latino-am Enfermagem. 2005;maio-junho;13(3):382-7

3- Mattia AL, Rocha AM, Freitas Filho JPA, Barbosa MH, Rodrigues MB, Oliveira MG. Análise das dificuldades no processo de doação de órgãos: uma revisão integrativa da literatura. Rev.Bioethikos. 2010;4(1):66-74.

4- Roza BA. Efeitos do processo de doação de órgãos e tecidos em familiares: intencionalidade de uma nova doação [tese]. São Paulo (SP): Universidade de São Paulo; 2005.

5- Brasil, Leis, etc. Decreto n.2.268 de 30 de junho de 1997. Regulamenta a Lei n 9.434, de 4 de fevereiro de 1997. Dispõe sobre a remoção de órgãos e tecidos e partes do corpo humano para fins de transplantes e tratamento e dá outras providências. Diário Oficial da União. Brasília, 1 jul. 1997; seção 1.

6- Teixeira RK, Gonçalves TB, Silva JA. A intenção de doar órgãos é influenciada pelo conhecimento populacional sobre morte encefálica? Ver. Bras. Ter. Intensiva. 2012; 24(3):25862.

7- Lemes MM, Bastos MA. Os cuidados de manutenção dos potenciais doadores de órgãos: estudo etnográfico sobre a vivência da equipe de enfermagem. Ver. Latino-am Enferm. 2007;15(5):986-91.

8- Escobar EM. Importancia de los cuidados intensivos en la donación y el trasplante de órganos. Ver. Bras. Ter. Intensiva. 2012;24(4):316-7.

9- Araujo MN, Massarollo MCKB, Conflitos éticos vivenciados por enfermeiros no processo de doação de órgãos, Acta Paul. Enferm. 2014;27(3):215-20.

10-Maya-Álvarez JA, Lechuga-García R, Querevalú-Murillo W. Social medicine servisse o funder graduate medicine students in the Hospitalary Donation Coordination area of the Mexi $\neg$ can Institute of Social Security. Rev.Med Inst Mex Seguro Soc. 2012;50(1):47-51.
11-Knihs, NS, Aplicação de instrumentos de qualidade em doação de órgãos e transplantes da Espanha validados em hospitais pilotos em Santa Catarina. J Bras Nefrol. 2015;37(3):323-32

12-Denvir P, Pomerantz A. A qualitative analysis of a significant barrier to organ and tissue donation: receiving less-than-op 7 timal medical care. Health Commun. 2009;24(7):597-607.

13-Cinque VM, Bianchi ERF. Estressores vivenciados pelos familiares no processo de doação de órgãos e tecidos para transplante. Rev. Esc. Enferm. USP. 2010; 44:996-1002. DOI: http://dx.doi.org/10.1590/S0080623420100004000020

14-FERRAZ, AS. Revisão Integrativa: indicadores de resultado processo de doação de órgãos e transplantes. J Bras Nefrol. 2013;35(3):220-8.

15-Secretaria Executiva de Saúde Publica do Estado Pará. Central de Transplantes. Disponível em http://www.saude. pa.gov.br, acesso em 23 de outubro de 2015, às 20:00 horas.

16-Claussel NO, Gonçalves LFS, Veronese FJV. Manutenção de doadores de órgãos. In: Rotinas em terapia intensiva. $3^{a}$ ed. Porto Alegre: Artmed; 2001.

17- Conceição AM, et al. Morte encefálica: um conceito a ser difundido. In: Day L. Morte Cerebral e doação de órgãos. In: Schell HM, Puntilho KA. Segredos em enfermagem na terapia intensiva. Porto Alegre: Artmed; 2005.

18-Morais M, Silva RCMA, Ramalho HJ, Silva R, Rita C.M.A. Silva; Renato F. Silva; Mário Abbud-Filho, As organizações de procura de órgãos são efetivas? Análise de sete anos de atividade de uma OPO brasileira. Arq Ciênc Saúde 2004;11(4):225-9

19-Morais M, Felicio HCC, Silva RCMA, Ramalho HJ, Silva, RF, Abbud MF. Avaliação das causas de não efetivação de doações de múltiplos órgãos em uma Organização de Procura de Órgãos (OPO) Regional. JBT 2001;1(4):1-4.

20-Arcanjo RA, Oliveira LC, Silva DD. Reflexões sobre a comissão intra-hospitalar de doação de órgãos e tecidos para transplantes, Rev Bioét (Impr.) 2013;21(1):119-25. 